\title{
A formação de professores online contribui para a literacia digital docente? Estudo de caso em curso de formação docente online no Brasil
}

\author{
Elaine Jesus Alves*, Bento Duarte da Silva** \\ *Universidade Federal do Tocantins, **Universidade do Minho
}

\begin{abstract}
Resumo
Na Sociedade em Rede a formação de professores online para a literacia digital constitui um debate relevante. Este artigo apresenta dados da pesquisa de doutoramento Formação de professores, Literacia Mediática e Inclusão Sociodigital: Estudo de caso em curso a distância da Universidade Federal do Tocantins cujo objetivo é compreender as implicâncias da formação docente online na literacia digital dos professores no cotidiano e práticas pedagógicas. A pesquisa qualitativa valeu-se de questionários e entrevistas com professores cursistas de licenciatura online. Constatou-se que estes utilizam as tecnologias de forma instrumental no cotidiano e os dados mostraram que possuem baixa literacia digital na prática pedagógica. O estudo aponta para a necessidade de cursos de formação com foco na literacia digital. Palavras chave: formação de professores online, Literacia digital, inclusão sociodigital.
\end{abstract}

\section{Contextualização}

No início do século XXI os professores voltaram a ocupar um lugar estratégico nas políticas públicas educacionais com foco no futuro da escola frente à crescente disseminação e apropriação das tecnologias pelos alunos. Ao mesmo tempo que cursos de formação inicial e continuada mediados por tecnologias são ofertados aos professores para seu aperfeiçoamento, estudos recentes apontam para um déficit de literacia digital destes em relação ao uso social e crítico das tecnologias e sua eventual inserção na era digital (Silva \& Cilento, 2014).

Castell (2003), ao conceber o conceito "Sociedade em Rede" analisa que a internet afetou a economia (forma de organização das empresas e indústrias), alterou os processos de trabalho (jornadas e formas de trabalho), mudou a estrutura da política, impactou os relacionamentos sociais, fortaleceu os movimentos sociais, ampliou o comércio e criou novas formas de ensinar e se aprender no campo da educação. A mobilidade proporcionada pelos telefones celulares modernos (smartphones) e os tablets possibilitam acesso às redes em qualquer lugar, a qualquer momento. Neste sentido, surgem novos espaços de aprendizagem além dos muros das escolas. O Tablet e os celulares conectados à internet imergem como dispositivos "cheios" de informações em contraste com o quadro-negro que, "vazio", precisa de um professor para que lhe escreva os conteúdos (Nóvoa, 2015). Por permitir o acesso a informações em qualquer hora, lugar e circunstâncias, os dispositivos móveis inauguraram um fenômeno novo: a aprendizagem ubíqua. Nas palavras de Santaella (2013, p. 26):

equipada com um dispositivo de conexão contínua, a pessoa pode saciar a sua curiosidade sobre qualquer assunto a qualquer momento e em qualquer lugar que esteja. O que emerge, portanto, é um novo processo de aprendizagem sem ensino.

Neste sentido, assim como a invenção da impressa no final da idade média mudou os paradigmas da educação, a revolução digital presente no nosso século XXI está a causar uma mudança significativa na sociedade contemporânea com reflexo na escola (Nóvoa, 2015) .

No entanto, no campo educacional a entrada das tecnologias enfrenta tensões. A presença de aparelhos celulares, tablets e computadores durante as aulas constitui ponto de controvérsia entre professores gestores e formuladores de políticas públicas. Educadores se queixam da dispersão dos alunos nas aulas e da dificuldade de conduzir as aulas enquanto os jovens estão trocando mensagens ou ouvindo músicas nos celulares e tablets. Mesmo quando o professor propõe uma atividade que requer pesquisa na internet, os alunos utilizam motores de busca, mas possuem baixo senso crítico em relação à credibilidade das informações, copiam e colam os textos sem referenciar as fontes e têm dificuldade em analisar, interpretar e construir textos a partir das leituras quase sempre rápidas em resumos (Lage \& Dias, 2012)

Desta forma, os professores nas aulas presenciais são desafiados a dialogar com os alunos, problematizar os acontecimentos da atualidade, despertar o interesse na pesquisa, propor atividades que integrem as mídias atuais. Sob esta perspectiva, os cursos de formação de professores online desempenham um papel fundamental na preparação dos professores no tocante a literacia digital, habilitando-os a se apropriarem das mídias nas suas práticas pedagógicas. A literacia digital trata da capacidade do indivíduo de acessar, analisar, compreender e avaliar de modo crítico as mídias e ainda criar comunicações em diferentes contextos (Lopes, 2013). Assim, a literacia vai além da dimensão técnica de saber aceder as informações na internet, mas implica na dimensão social, cultural, política e econômica do indivíduo. Portanto, os cursos de formação online deveriam consistir em espaços privilegiados para os professores desenvolverem práticas de literacia digital. No entanto, algumas propostas de cursos de formação online apresentam-se como uma reprodução do modelo tradicional de educação voltado para a transmissão e recepção de conteúdos. De acordo com Papert (1993, p. 127), as tecnologias digitais nestas propostas constituem "uma nova roupagem aos artefatos tecnológicos tradicionais (quadro, livros, cadernos) que serviam para transmitir ou replicar conhecimento". Programas de formação calcados em repositório de conteúdos e provas objetivas impedem a inventividade e a construção de 
sentidos dos professores sobre o trabalho coletivo e limitam suas possibilidades de trabalhar com mídias integradas em projetos pedagógicos.

Considerando estes pressupostos, a pesquisa que deu origem a este texto buscou investigar se os cursos de formação docente online contribuem para o desenvolvimento de práticas de literacia digital dos professores. Este artigo apresenta resultados parciais da pesquisa de doutoramento em Educação da Universidade do Minho intitulada: Formação de professores, Literacia Mediática e Inclusão Sociodigital: Estudo de caso em curso a distância da Universidade Federal do Tocantins.

O objetivo do estudo constitui investigar os impactos dos cursos de formação online de professores sobre as suas habilidades e competências para o uso das tecnologias digitais no seu cotidiano e práticas pedagógicas. As categorias de análise são: formação de professores, literacia digital ou mediática e inclusão sociodigital. A inclusão sociodigital seria uma possível consequência deste processo de apropriação técnica, social e cultural das tecnologias.

A estrutura deste texto traz inicialmente o quadro teórico sobre a formação docente online com foco na literacia digital dos professores nas atividades desenvolvidas com seus alunos. No segundo momento apresenta aspectos relacionados com o contexto e procedimentos metodológicos da pesquisa e finaliza apresentando resultados parciais desta revelando os possíveis impactos da formação online nas práticas de literacia digital dos professores participantes.

\section{A formação docente na contemporaneidade}

Autores contemporâneos têm investido discussão da necessidade de mudanças nas estruturas educacionais em face das mudanças que as tecnologias de comunicação e informação provocaram na sociedade (Nóvoa, 2015; Silva \& Cilento, 2014; Santos, 2014; Castell, 2014). Para Nóvoa (2009), o professor constitui peça central nesse processo. O autor lembra que nos anos de 1970, o foco era a pedagogia dos objetivos, do controle e planejamento. Nos anos de 1980, as reformas educativas eram centradas nas estruturas dos sistemas escolares e na engenharia do currículo; A década de 1990 foi marcada pela gestão e administração das organizações escolares. O autor argumenta, que nos dias atuais, a atenção está voltada à aprendizagem, e não se pode falar de aprendizagem sem destacar a figura do professor.

Neste contexto, políticas públicas para a formação do professor no campo do uso das tecnologias na prática docente vem sendo implementadas no decorrer deste século XXI. No Brasil, iniciativas como o Programa Nacional de Tecnologia Educacional (PROINFO), TV Escola, Salto para o Futuro, UCA (Um Computador por Aluno), Mídias na Educação, Plano Nacional de Formadores da Educação Básica (PARFOR), UAB, entre outras, constituem políticas públicas do governo federal para integrar as tecnologias no cotidiano dos professores e alunos da rede de ensino. No entanto, estudos recentes revelam que mesmo em formação online nesses programas, alguns professores encontram dificuldade com a fluência tecnológica, não apenas no uso instrumental das tecnologias mas também seu campo social e coletivo levando muitos a evadirem das formações (Ataíde, 2012; Meneses, 2011; Alves \& Faria, 2011). Almeida e Valente (2011) apontam a abordagem instrucionista dos cursos de formação online como um dos fatores para o insucesso da integração e apropriação das mídias pelos professores atendendo a grande massa de alunos por meio de transmissão de conteúdos via mídias tradicionais. Assim, os cursos são realizados em plataformas virtuais estáticas que constituem depositórios de conteúdos com pouca ou nenhuma interação.

Nóvoa (2009) defende que a formação de professores $a$ priori deve ocorrer nos espaços escolares. $\mathrm{O}$ autor cita o exemplo dos futuros médicos que durante a formação atuam como residentes em hospitais universitários, observam os pacientes, fazem relatórios de acompanhamento, supõem um diagnóstico e terapia e discutem com os colegas e com médico que os supervisionam, e ainda participam de seminários temáticos sobre as experiências. Do mesmo modo, os professores poderiam assistir aulas e fazer a mesma análise, discutindo à base das teorias de educação com os pares e professores experientes sobre a prática observada. Segundo Silva e Cilento (2014), o professor formado numa perspectiva de transmissão de saberes irá reproduzir esse modus operandi na sua prática docente. A coerência entre as exigências que se requer do professor: para que seja antenado, conectado e expert na integração das mídias no contexto escolar deve estar em sintonia com a sua formação. Ainda nas palavras de Nóvoa (2014) sobre a mudança de postura imposta aos professores "não podemos exigir-lhe quase tudo e dar-lhe quase nada". Portanto, os cursos de formação online deveriam constituir um espaço privilegiado para possibilitar ao professor vivenciar as tecnologias e apropriar-se delas de modo reflexivo na sua prática pedagógica.

\section{A literacia digital na formação de professores}

Retomando ao conceito de literacia digital, esta poderia ser definida como a capacidade do indivíduo de desenvolver tanto a compreensão crítica e interpretação de informações midiáticas como ser capaz de fazer um julgamento de valor e até mesmo produzir suas próprias mídias (Sousa, 2011). Sobre os desafíos impostos na formação de professores para a literacia digital está o choque geracional dos "imigrantes digitais" (professores offline) "nativos digitais" (alunos online), usando a terminologia de Prensky (2001). Ou, usando a analogia de White e Cornu (2011), os professores são “visitantes” e os jovens conectados são "residentes". O visitante acessa a internet para resolver questões práticas do cotidiano (ler email, pagar conta, ver noticiário) e desconectam sem deixar uma identidade digital. Em geral não participam de redes sociais e não se sentem pertencentes ao mundo digital, o visitam e saem. Já os residentes mantêm-se conectados o dia todo, em casa no computador fixo, no trabalho, no celular ou tablets enquanto está na rua. O mundo digital lhes pertence, eles residem nele e deixam rastros da sua identidade participando em blogs, redes sociais, comunidades e fóruns específicos. Logicamente, alguns professores se adaptaram às tecnologias e são "residentes", mas em geral, o perfil do professor no tocante aos artefatos 
tecnológicos consiste em usá-los basicamente para questões cotidianas práticas sem interesse em desenvolver relações de interatividade principalmente com seus alunos.

Sobre os obstáculos apontados à mudança de postura do professor em relação as tecnologias, Silva (2011) aponta o fator da necessidade da "imersão cibercultural”, ou seja, "um desraizamento de uma cultura comunicacional pedagógica tradicional” e consequente readaptação e apropriação dos professores, alunos e organizações educativas às tecnologias de comunicação e informação emergentes. O autor enfatiza que a formação continuada para a utilização pedagógica das tecnologias trata-se de uma estratégia basilar para a inclusão dos professores no ciberespaço e na cibercultura. Silva conclui que uma formação deficiente deixaria os professores a mercê de uma "pedagogia transmissiva e desfasada do contexto contemporâneo". De acordo com Freitas (2010, p. 348), o aluno "nativo digital” leva para a escola o que pesquisou nas suas navegações na rede e em geral está disposto a discutir com seus colegas e principalmente com o seu professor. No contexto atual o aluno faz essa pesquisa na própria sala de aula, enquanto o professor ainda está falando, ele busca novas informações na rede no seu celular ou tablet conectado. Assim, o professor não é visto como o único detentor e transmissor de conhecimento. Segundo a autora, a possibilidade de acessar a internet, fazer pesquisas e conhecer os mais variados assuntos confere ao aluno um novo perfil, e consequentemente muda o perfil do professor: este deve "estar atento a essa nova fonte de informações para transformá-las, junto com os alunos, em conhecimento”.

Equipar as escolas com computadores, fornecer uma internet potente, doar tablets ou notebooks aos professores e alunos pode ser um bom começo para possibilitar a inclusão sociodigital dos mesmos, mas não é o suficiente para produzir práticas de literacia digital. Neste sentido, os cursos de formação devem ultrapassar as plataformas virtuais de aprendizagem, serem balizados no trabalho em equipe, no reforço dos projetos locais da escola, na interação com equipes multidisciplinares formadas em diversas áreas. Os projetos pedagógicos de tais formações devem contemplar momentos de exploração das ferramentas digitais, manuseio de suportes tecnológicos com reflexão nas potencialidades dos mesmos no auxílio à aprendizagem do aluno. Voltando à analogia da formação dos professores com a formação dos médicos, estes trabalham em equipes para resolverem casos complexos, estão em constante formação para conhecerem novas técnicas e aparelhos tecnológicos que o ajudarão na cura dos pacientes. Assim, também a formação de professores deve valorizar o trabalho em equipe para que os mesmos possam exercer a profissão em regime colaborativo, em rede com os pares e a sociedade. Após essa breve reflexão teórica sobre formação de professores online e a literacia digital, apresentamos o contexto da pesquisa, procedimentos metodológicos e em sequência os resultados.
Contexto da pesquisa e procedimentos metodológicos

A pesquisa trata de um estudo de caso realizado com professores que são cursistas de licenciatura mediada por tecnologias numa universidade pública no interior do Brasil. O curso de Licenciatura na modalidade a distância, usado para esta pesquisa faz parte do Programa Universidade Aberta do Brasil (UAB). A Universidade Federal do Tocantins aderiu ao sistema UAB em 2006 com a oferta de duas licenciaturas a distância. Atualmente a UFT oferta 4 licenciaturas em mais de 18 polos da UAB.

Os cursos no modelo da UAB são semipresenciais, os encontros presenciais são obrigatórios nos polos para avaliação da aprendizagem e/ou seminários temáticos. Os conteúdos do curso são disponibilizados no Ambiente Virtual de Aprendizagem (AVA) Moodle. No início da oferta, os alunos são convocados para um encontro presencial em que são inseridos no Moodle e participam de uma oficina instrumental para conhecerem as ferramentas do AVA. A partir de então, a mediação ocorre pelo computador.

Ao observar este modelo de educação a distância, na posição de coordenadora pedagógica do departamento responsável por esta modalidade na UFT, recebemos notificações dos coordenadores de cursos online, professores e tutores das dificuldades que os cursistas enfrentam com o manuseio das tecnologias. Questões mais frequentes são o baixo acesso à plataforma (muitos acessam apenas para fazer donwload de material didático) e pouca participação em fóruns de discussão. Diante destas constatações questionamos se os professores em processo de formação online sentiriam a vontade em utilizar as tecnologias na sua prática pedagógica. O curso escolhido iniciou sua primeira oferta em 2010 e optamos por escolher para amostragem os cursistas matriculados que ingressaram em 2010 e 2012 totalizando 32 alunos. A escolha por ambas categorias se deu para verificar se o tempo de curso favoreceu o desenvolvimento da literacia digital dos professores.

A pesquisa, de cunho qualitativo, trata de um estudo de caso em que se pretende "investigar um fenômeno contemporâneo no seu contexto real” (Yin, 2001). Neste sentido, os instrumentos metodológicos são questionários e entrevistas semiestruturadas com o objetivo de compreender os impactos da formação mediada por tecnologias na literacia digital dos professores. Apresentamos neste trabalho um breve recorte dos dados resultantes da tabulação do questionário e das entrevistas.

O estudo buscou conhecer o perfil de uso de tecnologias dos participantes no seu cotidiano e prática pedagógica. Para tal aplicou-se questionários enviados por email a todos matriculados no curso entre 2010 e 2012 (32 alunos), tendo respondido 25 (78\%). O questionário, elaborado no Google Docs, contemplava três partes: (i) o Perfil econômico, sociocultural e sobre uso da internet; (ii) escala do uso de tecnologias digitais no cotidiano; (iii) escala do uso de tecnologias digitais na prática pedagógica. A segunda e terceira parte do questionário foram elaboradas a partir de uma adaptação da escala AliDiP - Avaliação da Literacia Digital para Professores (Joly, et al., 2014) que mensura a competência docente no uso de tecnologias digitais no cotidiano e no contexto pedagógico, considerando dois fatores: competência instrumental e competência de 
gestão pedagógica. Na adaptação da AliDip para construção do questionário do nosso estudo, dividimos também a escala em dois fatores: uso das tecnologias no cotidiano e uso das tecnologias nas práticas pedagógicas. A primeira, denominada "Escala do uso de tecnologias digitais no cotidiano”, contempla 20 questões relativas a atividades cotidianas dos participantes e sua relação com as tecnologias. A segunda, que chamamos de "Escala do uso de tecnologias digitais na prática pedagógica”, é constituída por 15 questões relacionados a aplicação de estratégias didáticas mediadas por tecnologias e uso dos aplicativos digitais para interatividade com os alunos fora do ambiente formal das aulas, dentre outras questões.

Com o objetivo de aprofundar os impactos da formação mediada por tecnologias na literacia digital dos professores, realizou-se uma entrevista semi-estruturada com seis participantes do curso que responderam o questionário. Selecionamos uma amostra homogênea para as entrevistas, escolhendo os entrevistados pelos seguintes critérios: a amostra teria que contemplar ambos sexos; cursistas ingressantes em 2010 e 2012; cursistas atuantes e não atuantes em sala de aula; cursistas que morassem na capital do estado do Tocantins e os que morassem no interior.

\section{Perfil e percepções dos participantes sobre a formação online}

Sobre o perfil econômico, sociocultural e uso de internet levantado nos questionários, verificou-se que 48\% possuem renda de dois a quatro salário mínimos, são na maioria do sexo masculino (72\%), todos moram na zona urbana e quase metade (43\%) já atuam como professores na rede pública. Os dados revelaram que os participantes utilizam as tecnologias predominantemente de forma instrumental no seu cotidiano e na sala de aula. Com faixa etária média de 25 a 44 anos, utilizam a internet a menos de 10 anos e ainda estão a adaptar-se às tecnologias. Dos participantes, $48 \%$ já possuem outra graduação e 53\% dos que afirmam ser professores atuam a mais de 11 anos em sala de aula.

Nas questões relacionadas à índole sociocultural, 76\% afirmaram usar a internet para obterem informações sobre os acontecimentos atuais. Sobre tipo de programas culturais que os participantes têm acesso com mais frequência, 43\% afirmaram não participar de nenhuma programação cultural.

No que diz respeito ao acesso e uso da internet, os participantes afirmaram possuir nas suas residências: computador de mesa (34,8\%), notebook (78,3\%), impressora (43,5\%), ligação à internet (82,6\%), tablete (30,4\%), smartphone $(39,1 \%)$. Dos que possuem acesso internet em casa, 48\% do tipo de acesso é internet banda larga fixa e $48 \%$ internet banda larga via rádio. Dos que afirmaram não possuir internet em casa, três responderam que achavam o custo da internet elevado e não podiam pagar e dois participantes disseram acessar a rede em outros lugares. $\mathrm{O}$ fato dos participantes terem acesso à internet nos seus dispositivos móveis, no computador de mesa, na sua casa ou em outros lugares como na escola e no trabalho, não diz muito a respeito da literacia digital dos mesmos. Conforme explicitado por DiMaggio e Hargittai (2001), a questão é: o que as pessoas estão fazendo e o que elas são capazes de fazer quando estão online. Os autores criticam estudos que caracterizam a exclusão sociodigital medindo pelos números de acessos e quantidade de computadores com internet nas residências, com o argumento de que a ampliação do acesso a alguns grupos antes excluídos digitalmente, passa pela qualidade da conexão e o uso pleno das informações obtidas.

Neste sentido, a segunda parte do questionário, a escala do uso de tecnologias no cotidiano, sondou nos participantes a frequência e os tipos de usos que fazem da tecnologia nas suas rotinas diárias. Sobre a frequência, foram disponibilizados os tipos de dispositivos tecnológicos e quatro opções para marcarem a frequência de uso: não usa, usa esporadicamente, uso semanal e uso diário. Segundo os participantes, o dispositivo com uso mais frequente é o computador de mesa, tendo 96,\% afirmado usá-lo diariamente. O notebook também é utilizado por $70 \%$ dos participantes. O tablet aparece como um dispositivo com baixo uso pelos participantes (30\%), enquanto $72 \%$ afirmam usar celular com internet. Sobre as atividades mais comuns que realizam no celular é efetuar e receber chamadas (100\%), enviar e receber sms $(95,8 \%)$, tirar fotos $(70,8 \%)$ e acessar redes sociais $(54,2 \%)$. Nas entrevistas, um dos participantes falou sobre sua dificuldade com o uso das tecnologias:

Eu já não gosto de tecnologia, ainda preciso me adaptar a isso, não gosto muito de ficar em computador cinco seis horas durante o dia, isso não era minha prática. Participante 1

Sobre as atividades que realizam quando "visitam" o ciberespaço, os participantes mostraram-se propensos a evitar atividades mais complexas e limitam-se a tarefas simples. Como, por exemplo, comunicam com outras pessoas usando as redes (53\%), pesquisam na internet para compras (48\%), fazem compras online com certa frequência (40\%) e pesquisam sites educativos (40\%). Atividades que exigem um grau maior de literacia digital dos participantes são menos efetuadas: $28 \%$ afirmaram produzir e compartilhar vídeos algumas vezes; $36 \%$ disseram que eventualmente produzem apresentação com vídeos e imagens, e 68\% alegaram nunca efetuar transações bancárias pela internet. Observa-se, portanto, que os participantes da pesquisa utilizam a tecnologia no seu cotidiano, possuem dispositivos conectados à internet, porém, utilizam os mesmos de forma instrumental e elementar.

Os dados levantados sobre o uso das tecnologias nas práticas pedagógicas apontam para um uso limitado dos recursos tecnológicos na sala de aula. Criar apresentações em slides e projetar aos alunos foi a atividade mais frequente constatada nos questionários (28\% dos participantes afirmaram que muitas vezes fazem apresentações com aparelho datashow) e também nas entrevistas alguns participantes quando questionados sobre o uso das tecnologias na sala de aula, afirmavam que projetavam suas aulas com uso de slides:

$\mathrm{Eu}$ já tento, mas, eu uso é as tecnologias mais tradicionais: Datashow, pego vídeos levo, passo, passo aqueles slides mais tradicionais. Mas coisas modernas mesmo, eu não consigo. Por exemplo, interagir no WhatsApp. Participante 1

Percebe-se assim um uso instrumental da tecnologia na prática pedagógica pelos professores participantes da pesquisa, voltado a projetar na parede o que escreveriam 
no quadro-negro ou ligar a TV e passar vídeos para os alunos sem nenhuma discussão relevante. Segundo Silva e Cilento (2014, p. 219), a TV, o vídeo e o rádio por se tratarem de meios de comunicação unidirecional massivos são mais fáceis para apropriação docente porque operam no paradigma da pedagogia da transmissão, no qual os professores estão acostumados, ao passo que os meios digitais, tendo por base a autoria do usuário e interatividade, "demandam do professor nova postura comunicacional e superação da prevalência da prática docente unidirecional”.

Os questionários revelaram também que os participantes mantém pouca interação com os alunos fora dos espaços escolares. Sobre usar um ambiente virtual de aprendizagem para orientar as atividades dos alunos, 56\% responderam que nunca o fizeram, igualmente, $48 \%$ afirmaram que nunca usaram redes sociais para interagir com os alunos em tempos e espaços informais.

Neste sentido, os cursos de formação de professores mediados por tecnologia que reproduzem a pedagogia da transmissão, formarão professores que compreenderão as tecnologias como meros dispositivos de reprodução em massa de conteúdos e de baixa interatividade.

\section{Considerações finais}

Os resultados apresentados são prévias considerações dos dados levantados na pesquisa de doutoramento. A pesquisa, ainda em andamento, tem como perspectiva explorar de modo aprofundado os dados coletados nos questionários e apreender as expressões dos participantes nas entrevistas com o objetivo de compreender o processo formativo mediado pelas tecnologias, $\mathrm{e}$ verificar como estas afetam as práticas de literacia digital dos professores com foco nas suas atividades docentes.

Sobre a pergunta que este artigo lança no tema, se a formação online de professores contribui para a literacia digital docente, a resposta depende da proposta da formação. Conforme Almeida e Valente (2011, p. 47) apontam há dois extremos que devem ser evitados e que ocorrem nas formações de professor online: a ênfase no aspecto tecnológico, em que o uso instrumental da tecnologia é o cerne da proposta, partindo do pressuposto que o professor conseguirá integrar as mídias na prática pedagógica; e por outro lado, propostas que enfatizam o aspecto pedagógico considerando as tecnologias como mero suporte de informações, desconsiderando que as mesmas "estruturam os modos de pensar, comunicar, lidar com a informação e construir conhecimento”. No curso em questão, neste estudo, observamos uma proposta em que os conteúdos são valorizados em detrimento da interação entre os participantes, o que reflete nas práticas cotidianas e pedagógicas dos professores cursistas. Portanto, esta pesquisa aponta para a necessidade de políticas públicas voltadas para a formação de professores para a literacia digital.

\section{Referências}

Almeida, M. E., \& Valente, J. A. (2011). Tecnologias e curículo: trajetórias convergentes Almeida, M. E., \& Valente, J. A. (2011). Tecnologias e curículo: trajetórias convergentes ou ou divergentes. São Paulo: Paulus.

Alves, E. J., \& Faria, D. C. (2011). O curso de extensão Mídias na Educação na UFT: um estudo da evasão.
Anais do $5^{\circ}$ Congresso Brasileiro de Extensão Universitária. Porto Alegre: Universidade Federal do Rio Grande do Sul.

Ataíde, D. M. (2012). Letramento digital e formação de professores: potencialidades na perspectiva do Plano Nacional de Formação de Professores Parfor. Dissertação de mestrado, Universidade Federal do Tocantins, Programa de Mestrado em Letras, Araguaína.

Castell, M. (2003). A Galáxia da Internet. (M. L. Borges, Trad.) Rio de Janeiro: Jorge Zahar.

Castell, M. (07 de 04 de 2014). A obsolência da educação. Acesso em 23 de junho de 2015, disponível

em https://www.youtube.com/watch?v=eb0cNrE3I5g

DiMaggio, P. J., \& Hargitta, E. (2001). From the 'digital divide' to 'digital inequality': Studying Internet use as penetration increases. (C. f. Studies, Ed.) Working Paper.

Freitas, T. M. (dez de 2010). Letramento digital e formação de professores. Educação em Revista., 26(3).

Joly, M. C., Martins, R. X., Almeida, S. L., Silva, B. D., Araújo, A., \& Vendraminy, M. M. (2014). Avaliação da Literacia digital para professores. Brasília: Universidade de Brasilia.

Lage, M. O., \& Dias, A. M. (2012). Literacia Informacional e mediática no mundo digital e em contexto de ensino profissional: novo mito ou plano necessário de acção. Actas do Congresso Nacional de Bibliotecários, Arquivistas e Documentalistas. Lisboa.

Levy, P. (1999). Cibercultura. São Paulo: Editora 34.

Lopes, M. d. (2013). A literacia digital dos profesores do $2^{\circ}$ e $3^{\circ}$ ciclos das escolas do concelho de Viseu. Universidade Católica Portuguesa. Lisboa: Universidade Católica Portuguesa.

Meneses, S. C. (2011). Um computador por aluno: Era da inclusão digital. Anais do XXII SBIE - XVII WIE. Aracaju.

Moura, A. (2009). Geração Móvel: um ambiente de aprendizagem suportado por tecnologias móveis para a “Geração Polegar. Actas da VI Conferência Internacional de TIC na Educação Challenges, (pp. 50-78). Lisboa.

Nóvoa, A. (2009). Professores imagens do futuro no presente. Lisboa: Educa.

Nóvoa, A. (2014). Nada será como Antes. Revista Pátio.

Nóvoa, A. (jan/abr 2015 de 2015). Em busca da Liberdade. A pedagogia universitária do nosso tempo. Revista de Docência Universitária, 21-34.

Palfrey, J., \& Gasser, U. (2008). Born Digital. Nova Yorque: Basic Books.

Papert, S. (1993). A máquina das crianças: repensando a escola na era da informática. Porto Alegre: Artmed.

Prensky, M. (2001). Digital Game-Based Learning. Rio de Janeiro: McGraw-Hill.

Santaella, L. (2007). Linguagens Líquidas na era da mobilidade. São Paulo: Paullus.

Santaella, L. (abril de 2013). Desafios da ubiquidade para a educação. Revista Ensino Superior Unicamp, 19-28. 
Santos, E. (2014). Pesquisa-Formação na Cibercultura. Santo Tirso: Whitebooks.

Silva, B. D. (2011). Desafios à docencia online na cibercultura. In: J. A. Carlinda Leite, Políticas, Fundamentos e Práticas do Curriculo (pp. 206-218). Porto: Porto .

Silva, M., \& Cilento, S. A. (jul/dez 2014 de 2014). Formação de professores para a docência online:Considerações sobre um estudo de caso. Revista da FAEEBA - Educação $e$ Contemporaneidade, 23(2014), 207-218.

Sousa, V. M. (2011). A Educação para os Media em Portugal - Experiências, Actores e Contextos. Relatório de Estágio no projecto da Entidade Reguladora para a Comunicação Social, Universidade do Minho, Centro de Estudos de Comunicação e Sociedade.
Tori, R. (2010). Educação sem Distâncias. São Paulo: Senac.

White, D. S., \& Cornu, A. (setembro de 2011). Visitors and Residents: A new typology for online engagement. Perr Reviewed Jornal on the internet, 16(9).

Yin. (2001). Estudos de caso: planejamento e métodos. Porto Alegre: Bookman. 